\title{
Efeito da Suplementação de Bezerros com Blocos Multinutricionais sobre a Digestibilidade, o Consumo e os Parâmetros Ruminais ${ }^{1}$
}

\author{
Suzana Gomes de Freitas ${ }^{2}$, Harold Ospina Patiño ${ }^{3}$, Paulo Roberto Frenzel Mühlbach ${ }^{4}$, \\ Felix Hilário Diaz Gonzáles ${ }^{5}$
}

\begin{abstract}
RESUMO - Foi realizado um experimento para avaliar o efeito da suplementação de feno de Tifton (Cynodon dactylon), com blocos multinutricionais formulados com diferentes níveis de melaço, sobre a digestibilidade, o consumo e a uréia sangüínea. Foram utilizados quatro bezerros Hereford de aproximadamente um ano de idade, com peso médio no início do experimento de 196 kg. O delineamento experimental utilizado foi o quadrado latino, porém a fim de incluir o tratamento sem suplementação, os dados foram analisados em blocos casualizados. Os tratamentos foram: sem suplementação e suplementação com blocos elaborados com quatro níveis de melaço: 25; 30; 35 e 40\%. A suplementação aumentou a digestibilidade da matéria seca e matéria orgânica significativamente. Não foram encontradas diferenças significativas no consumo de MS entre tratamentos. A suplementação diminuiu o consumo de matéria seca de feno, gerando um coeficiente de substituição de 0,58, porém aumentou o consumo total de matéria seca, matéria orgânica e proteína bruta. Embora não tenha sido encontrada diferença significativa entre os tratamentos suplementados com blocos, o consumo de matéria orgânica digestível aumentou significativamente com a suplementação, bem como a uréia sangüínea. A fim de avaliar alguns parâmetros ruminais como pH e $\mathrm{N}-\mathrm{NH}_{3}$, foi realizado outro experimento com três bezerros Hereford fistulados no rúmen. Os tratamentos utilizados foram: feno de Tifton sem suplementação e suplementação com blocos com 25 e 30\% de melaço. O delineamento experimental utilizado foi quadrado latino 3 x 3. A suplementação não alterou o pH ruminal a níveis críticos para digestão da fibra, porém aumentou significativamente a concentração de $\mathrm{N}-\mathrm{NH}_{3}$ ruminal.
\end{abstract}

Palavras-chave: blocos multinutricionais, consumo, digestibilidade, parâmetros ruminais

\section{Effects of Multinutrient Blocks Supplementation of Calves on Digestibility, Intake and Ruminal Parameters}

\begin{abstract}
A trial was conduced to evaluate the effects of Tifton hay (Cynodon dactylon) supplemented with multinutrient blocks formulated using different molasses levels on digestibility, intake, and blood urea level. Four Hereford steers, one year old, weighing on average $196 \mathrm{~kg}$ in the beginning of the experiment, were assigned to a $4 \mathrm{x} 4$ latin square. The treatments were: Tifton hay and Tifton hay plus supplementation with either 25, 30, 35, and 40\% molasses levels in multinutrient blocks. However, to include the treatment without supplementation, data were analyzed in a completely randomized blocks design. Supplementation significantly increased dry matter and organic matter digestibility. There were no differences on dry matter intake between treatments. Supplementation decreased the hay intake, showing a substitution coefficient of .58. Supplementation increased significantly total dry matter, organic matter and crude protein intakes. Although there was no significant difference between the supplemented treatments, digestible organic matter and blood urea increased significantly with supplementation. Another trial was conduced with three Hereford steers fistulated in the rumen to determine the effects of supplementation on rumen $\mathrm{pH}$ and $\mathrm{N}-\mathrm{NH}_{3}$ levels, using a $3 \mathrm{x} 3$ latin square design. The treatments were: Tifton hay and Tifton hay plus supplementation with 25 and 30\% molasses levels in multinutrient blocks. Supplementation did not affect rumen $\mathrm{pH}$ but $\mathrm{N}-\mathrm{NH}_{3}$ concentration was significantly higher in treatments with blocks.
\end{abstract}

Key Words: multinutritional blocks, intake, digestibility, rumen fermentation patterns

\section{Introdução}

As pastagens, nas quais está baseada grande parte da produção de bovinos de corte no Brasil, apresentam uma marcada produção estacional. Em certas épocas do ano praticamente paralisam seu crescimento, apresentando baixa disponibilidade de matéria seca e deficiência de alguns nutrientes. Nestas condições, os animais encontram-se em desequilíbrio nutricional e o consumo de energia digestível torna-se o principal limitante do desempenho animal. O melhor aproveitamento de forrageiras

${ }^{1}$ Parte da dissertação de Mestrado da primeira autora, parcialmente financiada pela PROPESQ - UFRGS.

2 Zootecnista, aluna do PPG - Zootecnia - UFGRS. E.mail: sufreitas@conex.com.br

3 Zootecnista, D.Sc., Professor do PPG - Zootecnia - UFRGS. E.mail: ospina@orion.ufrgs.br

4 Zootecnista, D.Sc., Professor do PPG - Zootecnia - UFRGS. E.mail: muhlbach@orion.ufrgs.br

${ }^{5}$ Médico Veterinário, D.Sc., Professor da Faculdade de Veterinária - UFRGS. E.mail: felixgon@orion.ufrgs.br 
de baixa qualidade depende da fermentação realizada pelos microrganismos do rúmen, que necessitam de substratos energéticos, protéicos e minerais para o seu desenvolvimento e otimização da digestão dos componentes da fibra. Muitos trabalhos têm demonstrado que essas limitações podem ser corrigidas com a suplementação (energética/protéica/mineral), a qual permite a correção das deficiências de nutrientes, melhorando a eficiência de utilização e transformação da base forrageira em produto animal, em função da melhora do ambiente ruminal.

Existem diversas formas de realizar a suplementação: com grãos, subprodutos da agroindústria, sais proteinados, sais energéticos e por meio dos blocos multinutricionais. Este último tipo de suplemento, ao ser lambido pelo animal, permite o consumo restringido de uma mistura de ingredientes (melaço, uréia, farelos, sal mineral) compactados, de modo a fornecer nutrientes constantemente ao longo do dia (nitrogênio, energia, macro e microminerais). A utilização de blocos multinutricionais proporciona um bom funcionamento ruminal, sem as quedas bruscas do $\mathrm{pH}$ e os picos na concentração de amônia ruminal, típicos da suplementação convencional (Garmendia, 1994). Além dos benefícios nutricionais, os blocos oferecem vantagens do ponto de vista logístico, devido à sua versatilidade, facilidade de manejo, transporte e armazenamento.

A otimização do ambiente ruminal devida à suplementação com blocos multinutricionais tem demonstrado resultado no aumento do consumo de volumosos de baixa qualidade (Sansoucy et al., 1988), no ganho de peso (Araque \& Escalona, 1995), na produção de leite (Wanapat et al., 1999) e em melhora na atividade reprodutiva (Beretta et al., 1999). Contudo, o sucesso na fabricação e utilização de blocos multinutricionais depende do conhecimento dos processos de fabricação e de seus efeitos sobre algumas características que afetam o desempenho animal, principalmente em relação à variabilidade do seu consumo (Lobato \& Pearce, 1980b). Apesar de existirem vários fatores que influenciam o consumo como a palatabilidade, a qualidade do volumoso, a disposição dos blocos no potreiro, o número de animais por bloco e o tempo de armazenamento, a dureza do bloco é considerada a principal variável na determinação do consumo (Sansoucy et al., 1988). Alguns trabalhos citam que níveis elevados de melaço e uréia, bem como a proporção de aglutinantes diminui a dureza do bloco, possibilitando maiores consumos.
(Hinestroza \& Becerra, 1990; Araque \& Cortes, 1998; Freitas et al., 1999). Birbe et al. (1998a) observaram que o consumo de blocos multinutricionais variou entre 140 e $700 \mathrm{~g} / \mathrm{animal} / \mathrm{dia}$, dependendo do nível de melaço utilizado.

O objetivo deste experimento foi avaliar o efeito da suplementação com blocos multinutricionais, elaborados com níveis crescentes de melaço, sobre a resistência do bloco, a digestibilidade e o consumo do feno, o nitrogênio plasmático e alguns parâmetros ruminais de bezerros consumindo feno de Tifton.

\section{Material e Métodos}

O experimento foi conduzido no Departamento de Zootecnia da Faculdade de Agronomia da UFRGS. Foram utilizados quatro bezerros Hereford de aproximadamente um ano de idade, com peso médio de 196 kg no início do experimento. Os animais foram mantidos em gaiolas metabólicas durante a condução do ensaio de digestibilidade convencional, que foi dividido em três fases: adaptação, consumo máximo e coleta de fezes, cada uma delas com duração de sete dias. Durante o experimento, os animais foram pesados a cada sete dias, e durante todo o período tiveram acesso, à vontade, a água e sal mineral.

O volumoso utilizado foi feno de Tifton (Cynodon dactylon), fornecido inteiro. A composição bromatológica média do feno foi a seguinte: 77,29\% matéria seca (MS); 95,14\% matéria orgânica (MO); 7,15\% proteína bruta (PB); 79,53\% fibra em detergente neutro (FDN); 47,41\% fibra em detergente ácido (FDA) e 6,49\% lignina (LDA). Previamente ao início da fabricação dos blocos multinutricionais experimentais, foram realizados ensaios-piloto com blocos menores, de, aproximadamente, $200 \mathrm{~g}$, testando-se diversas reações químicas e formulações com diferentes ingredientes e níveis de melaço, até obter as características físico-químicas desejadas. Os ensaios-piloto permitiram definir o nível e os ingredientes utilizados. De posse desta informação, os blocos experimentais foram confeccionados antes do início de cada período. Foram utilizados blocos multinutricionais, de aproximadamente $3 \mathrm{~kg}$, formulados com níveis crescentes de melaço e a mistura dos ingredientes foi feita com auxílio de uma betoneira. A fim de correlacionar a dureza com o consumo foram identificados seis blocos por tratamento nos quais foi realizado o teste de resistência (Forsythe, 1975). A medida da dureza $\left(\mathrm{kg} / \mathrm{cm}^{2}\right)$ foi realizada com 
penetrômetro manual digital em três pontos de cada bloco: um central e dois laterais.

Os tratamentos avaliados foram: feno de Tifton sem suplementação e suplementação com os blocos elaborados com 25, 30, 35 e 40\% de melaço. As formulações utilizadas nos blocos multinutricionais encontram-se na Tabela 1 e sua composição bromatológica média, na Tabela 2.

As amostras de feno, blocos, sobras e fezes foram analisadas para MS, MO e PB (AOAC, 1995), FDN, FDA, e LDA (Van Soest \& Robertson, 1985). A energia bruta (EB) foi determinada em bomba calorimétrica (Parr, 1988). Para determinação de uréia plasmática, no primeiro dia do início da fase de consumo máximo, foram coletadas amostras de sangue na veia jugular de cada animal e, no plasma, foi determinada a concentração de uréia plasmática (mg/dL) utilizando o método enzimático de Berthelot (Bergmeyer, 1985).
O delineamento experimental utilizado foi o quadrado latino 4 x 4, entretanto, a fim de incluir o tratamento sem suplementação, os dados foram analisados em blocos casualizados. Isto foi possível depois de comprovado que o efeito do período não foi estatisticamente significativo. O teste de comparação de médias utilizado foi o Tukey e o programa estatístico utilizado, o SAS (1996), segundo o seguinte modelo:

$$
Y_{i j k}=M+B_{j}+T_{i}+E_{i j k}
$$

em que $\mathrm{Y}_{\mathrm{ijk}}=\mathrm{i}$-ésima resposta medida, no j-ésimo animal recebendo o i-ésimo tratamento, no k-ésimo período; $\mathrm{M}$ = efeito médio; $\mathrm{B}_{\mathrm{j}}=$ efeito do j-ésimo animal (bloco); $\mathrm{T}_{\mathrm{i}}=$ efeito do i-ésimo tratamento; $\mathrm{E}_{\mathrm{ijk}}=\mathrm{k}$-ésimo erro associado ao animal e tratamento. A resistência dos blocos foi analisada por delineamento inteiramente casualisado, utilizando o teste Tukey para comparação de médias.

Tabela 1 - Composição dos blocos multinutricionais

Table 1 - Composition of multinutrient blocks

\begin{tabular}{|c|c|c|c|c|c|c|c|}
\hline \multirow[t]{2}{*}{$\begin{array}{l}\text { Tratamento } \\
\text { Treatment }\end{array}$} & \multicolumn{4}{|c|}{$\begin{array}{c}\text { Ingredientes (\%) } \\
\text { Ingredient (\%) }\end{array}$} & \multirow[b]{2}{*}{$\mathrm{NaCl}$} & \multirow[b]{2}{*}{$\mathrm{Ca}(\mathrm{OH})_{2}$} & \multirow[b]{2}{*}{$\mathrm{H}_{3} \mathrm{PO}_{4}$} \\
\hline & $\begin{array}{c}\text { Melaço } \\
\text { Molasses }\end{array}$ & $\begin{array}{l}\text { Uréia } \\
\text { Urea }\end{array}$ & $\begin{array}{l}\text { F. Milho } \\
\text { Corn meal }\end{array}$ & $\begin{array}{c}\text { F. Trigo } \\
\text { Wheat bran }\end{array}$ & & & \\
\hline $\begin{array}{l}25 \% \text { melaço } \\
25 \% \text { molasses }\end{array}$ & 25 & 5 & 28 & 20 & 5 & 7 & 10 \\
\hline $\begin{array}{l}30 \% \text { melaço } \\
30 \% \text { molasses }\end{array}$ & 30 & 5 & 23 & 20 & 5 & 7 & 10 \\
\hline $\begin{array}{l}\text { 35\% melaço } \\
35 \% \text { molasses }\end{array}$ & 35 & 5 & 20 & 18 & 5 & 7 & 10 \\
\hline $\begin{array}{l}40 \% \text { melaço } \\
40 \% \text { molasses }\end{array}$ & 40 & 5 & 17 & 16 & 5 & 7 & 10 \\
\hline
\end{tabular}

Tabela 2 - Composição químico-bromatológica média dos blocos multinutricionais em matéria orgânica (MO), proteína bruta $(\mathrm{PB})$, cálcio $(\mathrm{Ca})$, fósforo $(\mathrm{P})$, equivalente protéico $(\mathrm{EP})$ e energia bruta $(\mathrm{EB})$.

Table 2 - Mean chemical composition of multinutritional blocks in terms of organic matter (OM), crude protein (CP), calcium (Ca), phosphorus $(P)$, protein equivalent (PE) and gross energy (GE)

\begin{tabular}{|c|c|c|c|c|c|c|}
\hline \multirow[t]{2}{*}{$\begin{array}{l}\text { Tratamento } \\
\text { Treatment }\end{array}$} & \multicolumn{6}{|c|}{$\begin{array}{l}\% \mathrm{MS} \\
\% D M\end{array}$} \\
\hline & $\begin{array}{l}\text { MO } \\
\text { OM }\end{array}$ & $\begin{array}{l}\mathrm{PB} \\
C P\end{array}$ & $\mathrm{Ca}$ & $\mathrm{P}$ & $\begin{array}{l}\mathrm{EP} \\
P E\end{array}$ & $\begin{array}{l}\mathrm{EB}(\mathrm{kcal} / \mathrm{g}) \\
G E(\mathrm{kcal} / \mathrm{g})\end{array}$ \\
\hline $\begin{array}{l}25 \% \text { melaço } \\
25 \% \text { molasses }\end{array}$ & 79,6 & 26,2 & 3,5 & 1,9 & 53,6 & 3,181 \\
\hline $\begin{array}{l}30 \% \text { melaço } \\
30 \% \text { molasses }\end{array}$ & 79,3 & 26,3 & 3,6 & 1,8 & 53,4 & 3,216 \\
\hline $\begin{array}{l}35 \% \text { melaço } \\
35 \% \text { molasses }\end{array}$ & 78,0 & 25,4 & 3,9 & 2,2 & 55,2 & 3,065 \\
\hline $\begin{array}{l}40 \% \text { melaço } \\
40 \% \text { molasses }\end{array}$ & 77,7 & 25,4 & 3,8 & 2,1 & 55,2 & 3,081 \\
\hline $\begin{array}{l}\text { Média } \\
\text { Mean }\end{array}$ & 78,7 & 25,8 & 3,7 & 2,0 & 54,4 & 3,136 \\
\hline CV (\%) & 1,21 & 1,86 & 4,37 & 9,79 & 9,33 & 2,36 \\
\hline
\end{tabular}


Para avaliação do efeito da suplementação com blocos multinutricionais sobre o pH e a concentração ruminal de $\mathrm{N}-\mathrm{NH} 3$, foi conduzido outro ensaio com três bezerros Hereford fistulados no rúmen. Os tratamentos utilizados foram: feno de Tifton sem suplementação e suplementação com blocos elaborados com 25 e $30 \%$ de melaço. As amostras de líquido ruminal foram coletadas no saco ventral do rúmen uma hora antes da primeira refeição (hora 0), e 1, 2, 3, 5, 7, 9 e 12 horas após a mesma. Imediatamente após cada coleta, foi medido o $\mathrm{pH}$, com um potenciômetro digital e o restante da amostra foi filtrada, acidificada com $\mathrm{H}_{2} \mathrm{SO}_{4}$ e armazenada no congelador, para posterior determinação da concentração de $\mathrm{N}-\mathrm{NH}_{3}$, utilizando a técnica de microdifusão descrita por Voigt \& Steger (1967). Os dados foram analisados estatisticamente em um delineamento experimental em QL 3 x 3, com parcelas subdivididas e as médias comparadas pelo teste Tukey.

\section{Resultados e Discussão}

As digestibilidades da MS e da MO aumentaram com a suplementação, embora não tenha sido detectada diferença significativa quanto ao nível de melaço utilizado (Tabela 3). O aumento na digestibilidade da MO, decorrente da utilização de blocos multinutricionais, foi equivalente a 14; 9,8; 11 e 9,4\% para os blocos com 25, 30, 35 e 40\% de melaço, respectivamente. Resultados semelhantes foram encontrados por Wu \& Liu (1995), em um experimento realizado com ovinos para avaliar o efeito de blocos de uréia-mineral sobre a digestibilidade da MO e da FDN de palha de arroz, de palha de arroz tratada (amônia e bicarbonato) e de feno de campo nativo. A digestibilidade da $\mathrm{MO}$ aumentou com o uso dos blocos: $13 \%$ (51,8 vs 58,4\%) com a palha de arroz; 4,5\% (57,6 vs $60,2 \%)$ com a palha de arroz tratada e $10,4 \%(53,0$ vs $58,5 \%$ ) com o feno de campo nativo. Da mesma forma, a digestibilidade da FDN aumentou 12,6\% (55,6 vs $62,6 \%$ ) com a palha de arroz, $4,4 \%$ (65,6 vs $68,5 \%)$ com a palha tratada e 4,8\% (66,2 vs 69,4\%) com o feno decampo nativo. A utilização deblocos multinutricionais, no presente experimento, permitiu aumentar os coeficientes de digestibilidade da FDN e da FDA entre 3 e $12 \%$ em relação ao feno sem suplementação. Aparentemente, os melhores coeficientes de digestibilidade da MO, da FDN e da FDA são conseqüência de uma melhor disponibilidade de nutrientes para o crescimento de microrganismos ruminais, possibilitando uma maior degradabilidade ruminal dos constituintes da parede celular dos volumosos. Os melhores valores dos coeficientes de digestibilidade encontrados quando foram utilizados blocos fabricados com $25 \%$ de melaço podem estar relacionados ao fato destes blocos permitirem otimizar o ambiente fermentativo do rúmen, através de uma melhor relação entre a energia fermentável e o nitrogênio degradável.

O nível de melaço utilizado na composição dos blocos afetou sua resistência (Tabela 4). Aqueles nos quais foram utilizados 35\% de melaço apresentaram resistência $17 \%$ superior àqueles em que foram utili-

Tabela 3 - Coeficientes de digestibilidade médios (\%) da matéria seca (MS), matéria orgânica (MO), energia bruta (EB), fibra em detergente neutro (FDN) e fibra em detergente ácido (FDA) para cada tratamento

Table 3 - Average dry matter (DM), organic matter (OM), gross energy (GE) neutral detergent fiber (NDF) and acid detergent fiber $(A D F)$ coefficients of digestibility (\%)

\begin{tabular}{lccccc}
\hline & \multicolumn{5}{c}{ Coeficiente de digestibilidade (\%) } \\
\cline { 2 - 6 } $\begin{array}{l}\text { Tratamento } \\
\text { Treatment }\end{array}$ & MS & MO & EB & FDN & FDA \\
\hline $\begin{array}{l}\text { Sem suplementação } \\
\begin{array}{l}\text { Without supplementation } \\
25 \% \text { melaço }\end{array}\end{array}$ & $66,30^{\mathrm{b}}$ & $68,58^{\mathrm{b}}$ & $71,43^{\mathrm{b}}$ & $73,46^{\mathrm{b}}$ & $66,31^{\mathrm{b}}$ \\
$\begin{array}{l}25 \% \text { molasses } \\
30 \% \text { melaço }\end{array}$ & $75,81^{\mathrm{a}}$ & $78,24^{\mathrm{a}}$ & $80,06^{\mathrm{a}}$ & $82,02^{\mathrm{a}}$ & $71,99^{\mathrm{a}}$ \\
$\begin{array}{l}30 \% \text { molasses } \\
35 \% \text { melaço }\end{array}$ & $72,51^{\mathrm{a}}$ & $75,32^{\mathrm{a}}$ & $75,24^{\mathrm{ab}}$ & $78,38^{\mathrm{ab}}$ & $70,58^{\mathrm{ab}}$ \\
$\begin{array}{l}35 \% \text { molasses } \\
40 \% \text { melaço } \\
40 \% \text { molasses }\end{array}$ & $73,24^{\mathrm{a}}$ & $76,35^{\mathrm{a}}$ & $77,30^{\mathrm{ab}}$ & $80,90^{\mathrm{a}}$ & $69,87^{\mathrm{ab}}$ \\
\hline
\end{tabular}

Médias seguidas de mesma letra na coluna não diferem significativamente pelo teste de Tukey a $15 \%$. Means followed by the same letter, in column, do not differ significantly by Tukey test at $15 \%$. 
zados 25 e $40 \%$ de melaço, não diferindo, porém, do tratamento no qual foi utilizado $30 \%$ de melaço. Os valores de resistência encontrados no presente trabalho são muito superiores aos apresentados por Birbe et al. (2000) em blocos feitos com 19, 22 e 31\% de melaço: 1,$9 ; 2,8$ e $1,3 \mathrm{~kg} / \mathrm{cm}^{2}$, respectivamente. A grande variabilidade dos dados encontrados na literatura relacionando o nível de melaço com a dureza dos blocos, deixa dúvidas em relação à confiabilidade da medida de resistência feita com penetrômetro manual, principalmente quando o nível de umidade é superior a 14\% (Birbe et al.,1998b). Ferbes et al. (1997) encontraram que blocos multinutricionais elaborados com $40 \%$ de melaço e armazenados durante 15, 30 e 45 dias apresentaram resistências de 2,34; 3,24 e $3,40 \mathrm{~kg} / \mathrm{cm}^{2}$, respectivamente. Portanto, existem outros fatores tais como: a relação entre os ingredientes utilizados, o tempo de armazenamento e o processo de compactação utilizado, que também são importantes na determinação da dureza do bloco.

A análise da relação entre a dureza e o consumo de MS dos blocos, feita por regressão linear, mostrou que não houve relação entre consumo e resistência. Estes dados contrastam com os obtidos por Birbe et al. (1998a), cujos blocos elaborados com 30\% de melaço e com diferentes forças de compactação encontraram resistências ao penetrômetro de 2,2; 2,8; 2,9; 3,9; 4,1 e 4,9 kg/cm2 e um consumo de MS do bloco de 3320; 3018; 1800; 900; 680 e 110 g/dia, respectivamente.

Tabela 4 - Valores médios da resistência dos blocos $\left(\mathrm{kg} / \mathrm{cm}^{2}\right)$ e do consumo de matéria seca (MS) de blocos multinutricionais ( $\mathrm{kg} / \mathrm{dia}$ )

Table 4 - Average values of block resistance $\left(\mathrm{kg} / \mathrm{cm}^{2}\right)$ and dry matter (DM) intake of multinutritional blocks ( $k g /$ day)

\begin{tabular}{lcc}
\hline $\begin{array}{l}\text { Tratamento } \\
\text { Treatment }\end{array}$ & $\begin{array}{c}\text { Resistência } \\
\text { Resistance } \\
\left(\mathrm{kg} / \mathrm{cm}^{2}\right) \\
\left(\mathrm{kg} / \mathrm{cm}^{2}\right)\end{array}$ & $\begin{array}{c}\text { MS } \\
\text { DM } \\
(\mathrm{kg} / \mathrm{dia}) \\
(\mathrm{kg} / \text { day })\end{array}$ \\
\hline $\begin{array}{l}25 \% \text { melaço } \\
25 \% \text { molasses }\end{array}$ & $6,16^{\mathrm{b}}$ & $2,51^{\mathrm{a}}$ \\
$\begin{array}{l}30 \% \text { melaço } \\
30 \% \text { molasses }\end{array}$ & $6,70^{\mathrm{ab}}$ & $2,63^{\mathrm{a}}$ \\
$\begin{array}{l}35 \% \text { melaço } \\
35 \% \text { molasses } \\
40 \% \text { melaço } \\
40 \% \text { molasses }\end{array}$ & $7,19^{\mathrm{a}}$ & $2,74^{\mathrm{a}}$ \\
\hline
\end{tabular}

Médias seguidas de mesma letra na coluna não diferem significativamente pelo teste de Tukey a $10 \%$.

Means followed by the same letter in column do not differ significantly by Tukey test at $10 \%$.
O consumo de todas as frações nutritivas do feno de Tifton diminuiu significativamente $(\mathrm{P}<0,10)$ com a inclusão de blocos multinutricionais na dieta (Tabela 5). Esta resposta é uma conseqüência do efeito de substituição realizado por animais que recebem suplementação. Todavia, este efeito foi aditivo, pois não afetou o consumo total de MS. A equação obtida para o coeficiente de substituição foi: $\mathrm{Y}=2,07418$ $0,24902 * X\left(R^{2}=0,73\right)$, que mostra que cada $\mathrm{kg}$ de aumento no consumo de bloco diminui 0,25 unidades percentuais no consumo de feno de Tifton (expresso em \% do peso vivo), equivalente a 0,579 $\mathrm{kg}$ MS. Osuna et al. (1996) suplementaram feno de Digitaria xumfolosis, Hall com blocos multinutricionais elaborados com 25, 32,5 e 40\% de melaço e observaram, no entanto, que o consumo de feno não foi afetado (2,8; 2,9 e 3,1\% do peso vivo), entretanto, o consumo de blocos diminuiu com o aumento dos níveis de melaço nos blocos (1,0; 0,9 e $0,86 \%$ do peso vivo) sem que o consumo total de MS fosse afetado.

Apesar da variabilidade no consumo de blocos verificada em alguns trabalhos (Lobato \& Pearce, 1980a e 1980b, Preston \& Leng, 1989, Birbe et al., 1998b, Birbe et al., 2000), neste experimento, os blocos multinutricionais tiveram boa aceitabilidade e seu consumo foi bastante elevado (Tabela 5). Isto ocorreu, provavelmente, devido ao fato de os animais estarem em gaiolas metabólicas, com fácil acesso aos blocos e sem a competição com outros animais. Birbe et al. (1998a) também verificaram consumos elevados de blocos (3,018 a 3,320 kg/dia) elaborados com $30 \%$ de melaço e $9 \%$ de uréia, apesar das novilhas terem acesso aos blocos durante apenas 3 horas/dia.

Os consumos de MS, MO e PB, expressos em \% PV, do tratamento sem suplementação foram significativamente inferiores $(\mathrm{P}<0,10)$ aos dos demais tratamentos, sem que o nível de melaço nos blocos afetasse estas respostas (Tabela 5). Entretanto, a suplementação aumentou o consumo de MO digestível $(\mathrm{p}<0,10)$ provavelmente devido a maior e mais constante suprimento de nutrientes para o crescimento dos microrganismos ruminais que digerem fibra. Schiere et al. (1989) verificaram que o consumo de MS total de bovinos recebendo palha de arroz suplementada com blocos aumentou 7,5\% em relação à palha de arroz não suplementada. $\mathrm{O}$ consumo de MS digestível para os bovinos não suplementados foi de $57,8 \mathrm{~g} / \mathrm{kg}^{0,75} /$ dia e para os suplementados foi de $60 \mathrm{~g} / \mathrm{kg}^{0,75} / \mathrm{dia}$. 
Tabela 5 - Consumo médio de matéria seca (MS), matéria orgânica (MO), proteína bruta (PB) e matéria orgânica digestível (MOD) do feno de Tifton e do bloco, expresso em porcentagem do peso vivo (\%PV) e em gramas por unidade de tamanho metabólico ( $\mathrm{g} / \mathrm{kg} 0,75 / \mathrm{dia})$

Table 5 - Average dry matter (DM), organic matter (OM), crude protein (CP) and digestible organic matter (DOMI) intakes of Tifton hay and multinutrient blocks as live weight percentage (\%LW) and related to the metabolic weight $(\mathrm{g} / \mathrm{kg} \quad 0.75 / \mathrm{day})$

\begin{tabular}{|c|c|c|c|c|c|c|c|}
\hline \multirow[t]{3}{*}{$\begin{array}{l}\text { Tratamento } \\
\text { Treatment }\end{array}$} & \multicolumn{6}{|c|}{$\begin{array}{c}\text { Consumo (\%PV) } \\
\text { Intake }(\% L W)\end{array}$} & \multirow[b]{3}{*}{$\begin{array}{l}\operatorname{CMOD}\left(\mathrm{kg}^{0.75} / \mathrm{dia}\right) \\
\operatorname{DOM}\left(\mathrm{kg}^{0.75} / \text { day }\right)\end{array}$} \\
\hline & \multicolumn{2}{|c|}{$\begin{array}{l}\text { MS } \\
D M\end{array}$} & \multicolumn{2}{|c|}{$\begin{array}{l}\text { MO } \\
\text { OM }\end{array}$} & \multicolumn{2}{|c|}{$\begin{array}{l}\mathrm{PB} \\
C P\end{array}$} & \\
\hline & $\begin{array}{c}\text { Feno }^{1} \\
\text { Hay }\end{array}$ & $\begin{array}{l}\mathrm{BM}^{2} \\
M B^{2}\end{array}$ & $\begin{array}{c}\text { Feno }^{1} \\
\text { Hay }\end{array}$ & $\begin{array}{c}\text { Feno }^{2} \\
M B^{2}\end{array}$ & $\begin{array}{l}\mathrm{BM}^{2} \\
\text { Hay }\end{array}$ & $\begin{array}{c}\text { Feno }^{2} \\
M B^{2}\end{array}$ & \\
\hline Sem suplementação & $2,12^{\mathrm{a}}$ & - & $2,01^{\mathrm{a}}$ & - & $0,15^{\mathrm{a}}$ & - & $62,495^{b}$ \\
\hline $\begin{array}{l}25 \% \text { melaço } \\
25 \% \text { molasses }\end{array}$ & $1,48^{\mathrm{b}}$ & $1,19^{\mathrm{a}}$ & $1,41^{\mathrm{b}}$ & $0,85 a$ & $0,11^{\mathrm{b}}$ & $0,28^{\mathrm{a}}$ & $91,175^{\mathrm{a}}$ \\
\hline $\begin{array}{l}30 \% \text { melaço } \\
30 \% \text { molasses }\end{array}$ & $1,37^{\mathrm{b}}$ & $1,14^{\mathrm{a}}$ & $1,30^{\mathrm{b}}$ & $0,89 a$ & $0,10^{\mathrm{b}}$ & $0,30^{\mathrm{a}}$ & $85,563^{\mathrm{a}}$ \\
\hline $\begin{array}{l}35 \% \text { melaço } \\
35 \% \text { molasses }\end{array}$ & $1,36^{\mathrm{b}}$ & $1,15^{\mathrm{a}}$ & $1,29^{b}$ & $0,95 a$ & $0,10^{\mathrm{b}}$ & $0,29^{a}$ & $87,150^{\mathrm{a}}$ \\
\hline $\begin{array}{l}40 \% \text { melaço } \\
40 \% \text { molasses }\end{array}$ & $1,39^{b}$ & $1,05^{\mathrm{a}}$ & $1,32^{b}$ & $0,89 a$ & $0,10^{\mathrm{b}}$ & $0,29^{a}$ & $83,775^{a}$ \\
\hline
\end{tabular}

${ }^{1}$ Feno de Tifton (Tifton hay); ${ }^{2}$ bloco multinutricional (multinutrient blocks).

Médias seguidas de mesma letra na coluna não diferem significativamente pelo teste de Tukey a $10 \%$.

Means followed by the same letter in rows do not differ significantly by Tukey test at $10 \%$.

Nos dados sobre o pH do líquido ruminal não foi detectada significância na interação horário por tratamento, mostrando que a utilização de blocos multinutricionais não afetou este parâmetro ruminal durante o período de amostragem. $\mathrm{O}$ pH ruminal não foi reduzido a níveis críticos para a digestão da fibra. Segundo Dixon \& Stockdale (1999), o pH ótimo para digestão da fibra está na faixa de 6,6 a 7,0, sendo esta severamente reduzida quando o $\mathrm{pH}$ for menor que 6,2 e muito prejudicada quando o $\mathrm{pH}$ for menor que 6,0. Da mesma forma, os dados não apresentaram grandes variações ao longo do dia, mesmo nos horários logo após a primeira refeição. As flutuações no pH podem ser mais nocivas à população microbiana e à atividade celulolítica do que um $\mathrm{pH}$ baixo constante, devido ao estresse que significa ajustar-se atais mudanças (Shriver et al., 1986).

Conforme o esperado, os tratamentos que receberam suplementação com blocos multinutricionais apresentaram concentrações de $\mathrm{N}_{-} \mathrm{NH}_{3}$ significativamente superiores ao tratamento sem suplementação devido ao acréscimo de uréia na dieta dos animais suplementados (Tabela 6). O nível considerado ótimo para concentração de amônia ruminal é de 10 mg/dL, todavia, este valor não pode ser considerado estático, pois a capacidade das bactérias de sintetizar proteína e capturar amônia depende da taxa de fermentação de carboidratos (Van Soest, 1994). Preston \& Leng
(1989) indicaram valores entre 15 e $20 \mathrm{mg} / \mathrm{dL}$ de $\mathrm{N}$ $\mathrm{NH}_{3}$ para o ótimo crescimento dos microrganismos ruminais em dietas com altos teores de fibra. Desta forma, o tratamento sem suplementação apresentou um valor médio inferior ao ótimo, segundo os autores citados. Nos tratamentos com suplementação, além das concentrações médias de $\mathrm{N}-\mathrm{NH}_{3}$, no líquido ruminal, estarem dentro da faixa ótima, mantiveram uma maior estabilidade ao longo do dia.

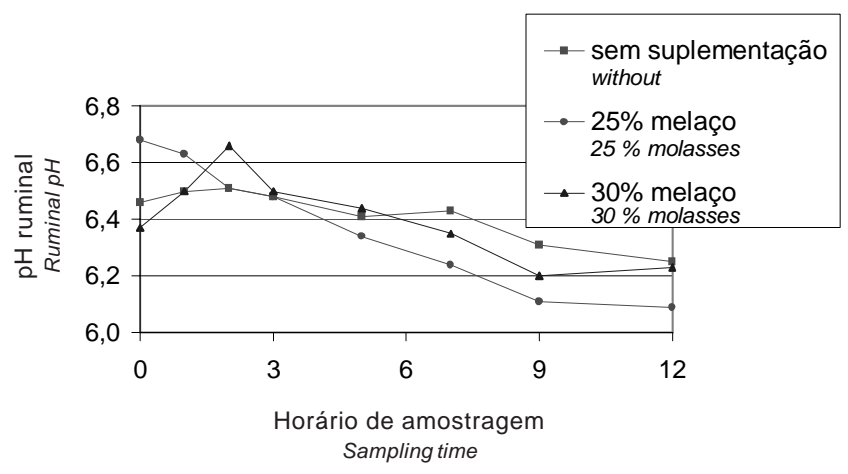

Figura 1 - Flutuações no pH ruminal por horário de coleta e tratamento.

Figure 1 - Ruminal $\mathrm{pH}$ fluctuation, according to the sampling time and treatment. 
Tabela 6 - Valores médios de $\mathrm{N}-\mathrm{NH}_{3}$ do líquido ruminal (mg/dl) para os tratamentos e horários de amostragem após a refeição

Table 6 - Average $\mathrm{N}-\mathrm{NH}_{3}$ ruminal fluid values $(\mathrm{mg} / \mathrm{dl})$ for treatments and post-feeding sampling time

\begin{tabular}{|c|c|c|c|}
\hline \multirow{3}{*}{$\begin{array}{l}\text { Hora da Coleta } \\
\text { Sampling time }\end{array}$} & \multicolumn{3}{|c|}{$\mathrm{N}-\mathrm{NH}_{3}(\mathrm{mg} / \mathrm{dl})$} \\
\hline & Sem Suplementação & 25\% melaço & $30 \%$ melaço \\
\hline & Without supplementation & $25 \%$ molasses & $30 \%$ molasses \\
\hline 0 & $5,8^{\mathrm{NS}}$ & $7,9^{\mathrm{NS}}$ & $4,9^{\mathrm{NS}}$ \\
\hline 1 & $6,5^{c}$ & $26,1^{\mathrm{a}}$ & $13,3^{b}$ \\
\hline 2 & $9,8^{b}$ & $22,2^{\mathrm{a}}$ & $24,5^{a}$ \\
\hline 3 & $9,3^{b}$ & $23,3^{\mathrm{a}}$ & $20,8^{a}$ \\
\hline 5 & $6,8^{b}$ & $23,2^{\mathrm{a}}$ & $24,5^{\mathrm{a}}$ \\
\hline 7 & $6,5^{b}$ & $19,6^{\mathrm{a}}$ & $21,5^{a}$ \\
\hline 9 & $5,6^{\mathrm{b}}$ & $16,1^{\mathrm{a}}$ & $15,9^{a}$ \\
\hline 12 & $4,7^{\mathrm{b}}$ & $12,4^{\mathrm{a}}$ & $13,8^{\mathrm{a}}$ \\
\hline Média & 6,9 & 18,9 & 17,4 \\
\hline \multicolumn{4}{|l|}{ Mean } \\
\hline $\mathrm{CV} \%$ & 25,92 & 33,08 & 38,70 \\
\hline
\end{tabular}

NS= não significativo (NS= not significant).

Médias seguidas de mesma letra na linha não diferem significativamente pelo teste de Tukey a 5\%.

Means followed by the same letter in rows do not differ significantly by Tukey test at $5 \%$.

Os valores da concentração de uréia sangüínea encontrados nesse experimento foram de: 12,$34 ; 20,80$; 25,76; 21,91 e 21,23 mg/dL para cada tratamento (sem suplementação, e suplementação com blocos com 25, 30, 35 e $40 \%$ de melaço), respectivamente. O tratamento sem suplementação foi significativamente inferior $(\mathrm{P}<0,15)$, entretanto não foi determinada diferença significativa entre os tratamentos com suplementação. A concentração de uréia sangüínea no tratamento sem suplementação permite identificar animais com deficiência de proteína na dieta. Pode-se afirmar que a elevação da uréia sangüínea está diretamente relacionada ao conteúdo de $\mathrm{PB}$ adicionada à dieta pela suplementação com blocos multinutricionais. A suplementação com blocos multinutricionais forneceu nitrogênio suficiente para elevar a concentração de N$\mathrm{NH}_{3}$ ruminal e, com isso, a concentração de uréia sangüínea também aumentou, porém, dentro de níveis considerados normais para bovinos de corte: entre 17 e $45 \mathrm{mg} / \mathrm{dL}$ (Kaneko et al., 1997).

\section{Conclusões}

A suplementação com blocos multinutricionais elaborados com 25\% de melaço aumentou os coeficientes de digestibilidade da matéria seca, matéria orgânica, energia bruta, fibra em detergente neutro e fibra em detergente ácido. Independentemente do nível de melaço utilizado, a suplementação com blocos aumentou o consumo de matéria seca total, proteína bruta total e matéria orgânica digestível. A suplementação com blocos não provocou alterações no pH ruminal críticas à digestão da fibra, mas elevou a concentração diária de nitrogênio uréico sanguíneo e de amônia ruminal, mantendo-a estável ao longo do dia. O nível de melaço utilizado e a resistência não estiveram relacionados entre si, assim como o consumo e a resistência. Há necessidade de se buscarem outros parâmetros de avaliação da dureza dos blocos a fim de relacioná-la ao consumo, para estabelecer um programa de suplementação com adequado consumo de suplemento.

\section{Literatura Citada}

ARAQUE, C.A.; ESCALONA, M. Una nota sobre el uso de los bloques multinutricionales en ganado de ceba. Zootecnia Tropical, v.13, n.1, p.87-94, 1995.

ARAQUE, C.A.; CORTES, R. Evaluación del efecto de diferentes niveles de urea en bloques multinutricionales sobre el consumo de los bloque y ganancia de peso en mautes. Revista Faculdad de Agronomia (LUZ), v.15, p.180-187, 1998.

ASSOCIATION OF OFFICIAL AGRICULTURAL CHEMISTS - AOAC. Official methods of analysis of AOAC International. 16.ed. Washington: 1995. p.1-79.

BERGMEYER, H.U. Methods of enzymatic analysis. Florida: VHC Publisher, 1985. v.9, 453p.

BERETTA, V.; HEINZEN, M.; SIMEONE, A. et al. Efeito da suplementação com blocos protéicos na evolução do estado nutricional e comportamento reprodutivo de vacas Hereford pastejando campo nativo diferido. In: REUNIÃO ANUAL DA SOCIEDADE BRASILEIRA DE ZOOTECNIA, 36., 1999, Porto Alegre. Anais... Porto Alegre: Sociedade Brasileira de Zootecnia, 1999. CD ROM

BIRBE, B.F.; CHACÓN, E.; TAYLHARDAT, L.A. et al. Aceptabilidad en bovinos de bloques multinutricionales conteniendo harina de Gliricidia sepium y roca fosforica. In: 
MEMORIAS DEL TALLER INTERNACIONAL SILVOPASTORIL, 3., 1998, Matanzas. Anais... Cuba: [s.n.], 1998a. p.166-170.

BIRBE, B.F.; CHACÓN, E.; TAYLHARDAT, L.A. et al. Evaluacion fisica de bloques multinutricionales conteniendo Harina de Gliricidia sepium y roca fosforica: energia de compactacion y humedad en la elaboración de mezcla. In: MEMORIAS DEL TALLER INTERNACIONAL SILVOPASTORIL, 3., 1998, Matanzas. Anais... Cuba: [s.n.], 1998b. p.161-165.

BIRBE, B.; GÚZMAN, Y.; HERRERA, P. et al. Aceptabilidad de bloques multinutricionales com fruto de y hoja de Cañafistolo (Caasia moschata) en bovinos. In: REUNIÓN LATINOAMERICANA DE PRODUCCIÓN ANIMAL; CONGRESSO URUGUAYO DE PRODUCCIÓN ANIMAL, 16., Montevideo, 2000. Anais... Montevideo: ALPA, 2000. CD-ROOM.

DIXON, M.R.; STOCKDALE, R. Associative effects between forages and grains: consequences for feed utilization. Australian Journal Agriculture Research, v.50, n.5, p.757773, 1999.

FERBES, A.; GADEA, J.; ROMERO, M. et al. Efecto de la dureza de los bloques multinutricionales sobre el consumo voluntário en bovinos mestiços. Archivos Latinoamericanos de Produccion Animal, v.5, p.214-216, 1997.

FORSYTHE, W. Fisica de suelos. San José: Editorial, 1975. 212p.

FREITAS, S.P.G.; OSPINA, H.P.; TREIN, C.R. et al. Efeito de quatro níveis de melaço e de bentonita sódica sobre algumas características físico-químicas de blocos multinutricionais. In: REUNIÃO ANUAL SOCIEDADE BRASILEIRA DE ZOOTECNIA, 36., 1999, Porto Alegre. Anais... Porto Alegre: Sociedade Brasileira de Zootecnia, 1999. CD ROM.

GARMENDIA, J.C.A. Uso de bloques multinutricionales en la ganaderia a pastoreo de forrajes de pobre calidad. Revista Faculdad de Agronomia (LUZ), v.11, n.2, p.224-237, 1994.

HINESTROZA, A.D.; BECERRA, M.J. Observaciones sobre la elaboracion y consumo de bloques urea-melaza. Livestock Research Rural Development, v.2, p.8-14, 1990.

KANEKO, J.J.; HARVEY, J.W.; BRUSS, M.L. Clinical biochemistry of domestic animals. 5.ed. New York: Academic Press, 1997. 907p.

LOBATO, J.F.P.; PEARCE, G.R. Responses to molasses-urea blocks of grazing sheep and sheep in yards. Journal Experimental Agricultural Husband, v. 20, p. 417-421, 1980a.

LOBATO, J.F.P.; PEARCE, G.R. Effects of some management procedures on the responses of sheep to molasses-urea blocks. Journal Experimental Agricultural Husband, v.20, p.422-426, 1980b.

OSUNA, D.; VENTURA, M.S.; CASANOVA, A. Alternativas de suplementacion para mejorar la utilizacion de forrajes consevados: II. Efecto de diferentes concentraciones de dos fuentes de energía en bloques nutricionales sobre el consumo e ganancia de peso de ovinos en crecimiento. Revista Faculdad de Agronomia (LUZ), v.13, p.191-200, 1996.
PARR INSTRUMENT COMPANY. Oxigen bomb calorimetry and combustion methods. Molline, 1988. (Technical Manual, 130).

PRESTON, T.R.; LENG, R.R. Produccion pecuária tropical: ajustando los sistemas de produccion pecuaria a los recursos disponibles aspectos basicos y aplicados del nuevo enfoque sobre la nutricion de rumiantes en el tropico. Colombia: [s.n.], 1989. 312p.

SANSOUCY, R.; AARTS, G.; LENG, R.A. Molasses-urea blocks as a multinutritional supplement for ruminants. In: SANSOUCY, R.; AARTS, G.; LENG, R.A. (Eds.). Sugar cane as feed. Santo Domingo, Dominicana Republic: FAO, 1988. Health. n.72, p.263-279.

SCHIERE, J.B.; IBRAHIM, M.N.M.; SEWALT, V.J.H. et al. Responses of growing cattle given rice straw lick blocks containing urea and molasses. Animal Feed Science Technology, v.26, p.179-189, 1989.

SHRIVER, B.J.; HOOVER, W.H.; SARGENT, J.P. et al. Fermentation of a high concentrate diet as affected by ruminal $\mathrm{pH}$ and digesta flow. Journal of Dairy Science, v.69, p.413, 1986.

Van SOEST, P.J.; ROBERTSON, J.B. Analysis of forages and fibrous foods. A laboratory manual for Animal Science 613. Cornell University, 1985. 202p.

Van SOEST, P.J. Nutritional ecology of the ruminant. 2.ed. Ithaca: Cornell University Press, 1994. 476p.

VOIGT, J.; STEGER, H. Zur quantitativen Bestimmung von Ammoniak, Harnstof und Ketoerpern im biologischen Material mit Hilfe eines modifizierten Mikrodiffusionsgefaesses. Archiv für Tierernaehrung, v.17, p.289-93, 1967.

WANAPAT, M.; ETLUM, A.; PIMPA, O. Strategic supplementation with high-quality feed block on roughage intake, milk yield and composition, and economic return in lactating dairy cows. Asian Australian Journal of Animal Science, v.12, n.6, p.901-903, 1999.

WU, Y.M.; LIU, J.X. The kinetics of fiber digestion, nutrient digestibility and nitrogen utilization of low quality roughages as influence by supplementation with urea-mineral lick blocks. First FAO Electronic Conference on Tropical Feeds and Feeding Systems, FAO Animal Production and Helth Paper. Food and Agriculture Organization on United Nation, 1995. 